\title{
Cost and emission impacts of virtual power plant formation in plug-in hybrid electric vehicle penetrated networks
}

\author{
Okan Arslan, Oya Ekin Karasan* \\ Department of Industrial Engineering, Bilkent University, Bilkent, 06800 Ankara, Turkey
}

\section{A R T I C L E I N F O}

\section{Article history:}

Received 3 January 2013

Received in revised form

16 August 2013

Accepted 19 August 2013

Available online 14 September 2013

\section{Keywords:}

PHEV

DER

VPP

V2G

Scheduling

Energy management

\begin{abstract}
A B S T R A C T
With increasing interest in alternative energy resources and technologies, mass penetration of PHEVs (plug-in hybrid vehicles) into the electricity grid and widespread utilization of DERs (distributed energy resources) are anticipated in the near future. As an aggregation unit, the VPP (virtual power plant) is introduced for load management and resource scheduling. In this article, we develop an energy management model for VPPs and analyze the cost and emission impacts of VPP formation and PHEV penetration. We conduct a case study for the state of California using real-world data from official resources. An average of $29.5 \%$ cost reduction and $79 \% \mathrm{CO}_{2}$ and $83 \% \mathrm{NO}_{x}$ emission reductions are attained as shared benefits of consumers in the case study. Results are illustrative of opportunities that VPP formation can provide for the community. Sensitivity of the results to the DER costs and capacities, battery and gasoline prices are also analyzed. In addition, we prove that charging and discharging do not simultaneously occur in the solutions, which leads to a simplification in traditional energy management models.
\end{abstract}

(c) 2013 Elsevier Ltd. All rights reserved.

\section{Introduction}

The development of environmental conscience leads to more green and renewable energy generation, as well as new energygeneration technologies. Mass penetration of PHEVs (plug-in hybrid vehicles) into the electricity grid and widespread utilization of DERs (distributed energy resources) such as microturbines, fuel cells, photovoltaic systems and wind systems are therefore anticipated in the future. PHEVs are also regarded as DERs due to their ability to provide energy for the grid. Despite their benefits, using PHEVs as a type of DER complicates the energy resource scheduling problem, and aggregating several different generation units further compounds this challenge. With these changes, energy scheduling is an emerging subject in the literature.

Several electricity suppliers and DERs can be brought together to satisfy the demand load. The VPP (virtual power plant), a newly introduced aggregation unit, is responsible for load management and resource scheduling. It obtains energy from the DERs, and contracts with the consumers in order to supply energy to their

\footnotetext{
* Corresponding author.

E-mail addresses: okan.arslan@bilkent.edu.tr (O. Arslan), karasan@bilkent.edu.tr (O.E. Karasan).
}

PHEVs and residential loads. To this end, it creates economies of scale in a whole new way [1]. VPPs minimize the total cost while ensuring that the energy generated by the DERs is efficiently used. They have no large-scale infrastructure requirements and can interact with the smallest DERs with higher efficiencies and more flexibility [2]. This new technology is usually referred to as the 'Internet of energy' [1]. Some real-world examples of VPPs are presented by Nikonowicz and Milewski [3].

The terms VPP and microgrid are usually used interchangeably with a slight difference that the microgrid can be 'islanded' from the grid whereas the VPP must be connected to the grid [1]. The aggregator centrally controls energy distribution to a set of consumers with TE (time-elastic) and TIE (time-inelastic) loads. The latter, such as refrigeration or heating, must be satisfied as soon as demanded, whereas the former, such as PHEVs, can be scheduled as desired during the connection period. For instance, the PHEV owner connects the vehicle to the electricity grid after returning from work in the evening and needs the battery fully charged by morning. If needed, the aggregator can discharge energy from the PHEV at any time during the night as long as the battery has reached its demanded level by morning.

Fig. 1 depicts VPP energy scheduling process. The electricity suppliers and DERs are referred to as EPs (energy providers) within the context of this study. Energy transfers between EPs, VPP, the PHEVs and houses, i.e., TIE loads, are depicted by the arrows. 


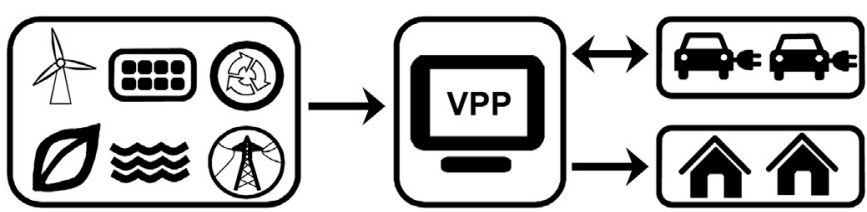

Fig. 1. Energy scheduling process.

\subsection{Problem definition}

Our problem is the energy management of a VPP in a PHEVpenetrated network. We assume that a group of people come together to form the VPP in order to minimize the cumulative cost and to benefit from the economies of scale. In the present setting, this group is obtaining electricity from the national grid with respect to different tariffs. With the VPP formation, they will become eligible to attain energy from a different set of EPs for potential cost reduction. In this context, there are a number of EPs, including, but not limited to, photovoltaic units, solar and wind farms, fuel cells, hydrogen fuel cells, biomass units and the national grid. The cost for obtaining energy from EPs varies through time. Each EP has an efficiency percentage and a minimum and a maximum power limit. The VPP is responsible for obtaining the required level of energy from the EPs and delivering the energy to a set of consumers with TE and TIE loads. If required, the VPP can also obtain energy from PHEV batteries by discharging them. Preemption (job splitting) is allowed for PHEV battery charging. The PHEV battery has a charging efficiency, which is the percentage of the provided energy that it can actually store. Similarly, the discharge efficiency is the percentage of the energy that it can provide to the VPP from the energy stored in its batteries. Each PHEV has an initial level of charge; and it charges, discharges and consumes energy throughout the day. PHEVs need a minimum level of energy and the battery charge level cannot go below this level. A PHEV travels in a $\mathrm{CD}$ (charge-depleting) mode as long as the state-of-charge of the battery is above the minimum level, and switches to a CS (chargesustaining) mode, traveling using gasoline, once the battery reaches the minimum charge level.

Charge and discharge scheduling is a shared decision between the PHEV owner and the VPP. The PHEV owner decides when to connect, how long the connection will last and the mileage to be traveled in each trip. The VPP is responsible for charge and discharge scheduling decisions and it provides the energy for the PHEV, taking into account the gasoline and electricity generation costs. The VPP achieves this responsibility by dispatching the EPs as necessary.

\subsection{Literature review}

The problem of microgrid energy scheduling for a forecast load with the objective of cost minimization is addressed from several different aspects in the recent literature [4-20]. Aside from the microgrid energy scheduling literature, different papers address the energy scheduling problem in PHEV-penetrated networks [2128]. Future trends of PHEVs [29-33] and emission impacts [34-36] are also considered. Even though an energy management methodology and/or market analysis models are presented, the common drawback is that the cost and emission impacts are not explicitly put forward. Sioshansi and Denholm [37] analyze the value of PHEVs as grid resources and model the charge scheduling of PHEV batteries. This is a unit commitment model of the ERCOT (Electricity Reliability Council of Texas) electric power system, formulated as an MILP (Mixed Integer Linear Program). The objective of the model is to minimize the total system cost, which consists of conventional generator costs and PHEV operation costs. The study considers the cost and emission impacts in the grid domain, but DERs and VPP are not considered in this study. A later study by Sioshansi [38] uses the same model and includes another model to make driving and charging decisions for the PHEV owner. Combining the two, the paper examines the incentives for individual drivers with different electricity tariffs. However, the ability to use PHEV batteries as storage is not included in the model. Sousa et al. [39] address the problem of energy scheduling from the VPP perspective, also considering technical constraints such as bus voltage magnitude and angle limits. The authors schedule PHEV battery charging and discharging by aggregating PHEVs into units of ten. The objective function of the model is defined to be cost minimization, but the charging price for PHEVs is added to the objective function with a negative coefficient. Therefore, the model actually minimizes the cost less the income, which implies profit maximization. Due to this representation, the objective function actually drives the solution to schedule PHEV charging at time intervals with higher costs. The presented objective value is always positive in this study because the income from TIE loads is not included in the objective function.

\subsection{Summary and contributions}

This paper investigates the cost and emission impacts of VPP formation in PHEV-penetrated networks. In the following section, we propose a new model that minimizes the total cost from the VPP viewpoint and we present an integer linear representation of the model. In Section 3, we consider a VPP formation in the state of California as a case study in order to determine the cost and emission changes from the case when the consumers obtain energy from the national grid. Furthermore, we conduct sensitivity analyses on the battery price, the gasoline price, DER price and capacities, and present extensive insightful results. We conclude the study with a discussion of the advantages of the VPP formation and potential future work directions.

\section{Modeling the problem}

This section is made up of two subsections: the first introduces the VPP energy management model, and the second deals with the battery degradation cost modeling.

\subsection{VPP energy management model}

The objective of the VPP energy management model is to minimize the total cost of energy in order to satisfy the loads and to generate the charging and discharging schedules of the PHEVs. The parameters and the variables to be used are presented below:

\section{- Parameters}

$V, U, T$ : Set of PHEVs, EPs and time periods

$I_{v, t}: 1$ if PHEV $v$ is available for charging during period $t$, and 0 otherwise

$l_{t}^{\mathrm{TIE}}$ : Energy demand to meet the TIE loads during period $t(\mathrm{kWh})$

$\bar{G}_{u, t}, \underline{G}_{u, t}$ : Maximum and minimum energy supply by EP $u$ during period $t$, respectively $(\mathrm{kWh})$

$\bar{P}_{v}, \underline{P}_{v}$ : Battery maximum and minimum energy capacity of PHEV $v$, respectively $(\mathrm{kWh})$

$\mathrm{PO}_{v}$ : Initial energy stored in battery of PHEV $v(\mathrm{kWh})$

$\rho_{v}^{+}, \rho_{v}^{-}$: Total energy transferable to/from PHEV $v$ during one time period, respectively ( $\mathrm{kWh}$ )

$\tau_{u}^{+}, \tau_{u}^{-}$: Minimum up and down times of EP $u$

$\eta_{u}^{\mathrm{EP}}$ : Efficiency of EP $u$ due to plant side and transformer losses 
$\eta_{v}^{+}, \eta_{v}^{-}$: Battery charge and discharge efficiency of PHEV $v$, respectively

$c_{u, t}^{\mathrm{EP}}$ : Price of obtaining energy from EP $u$ during period $t$ (paid by VPP to EPs) ( $\mathbb{c} / \mathrm{kWh})$

$c_{t}^{\text {gas }}:$ Price of gasoline during period $t$ ( $\mathbb{C} /$ gallon)

$\mathrm{Cs}_{v}$ : Average gasoline usage of PHEV $v$ (gallon/mile)

$d_{v, t}^{\text {total }}$ : Total travel distance during period $t$ by PHEV $v$ (miles)

$E_{v}$ : Energy required to run PHEV $v$ on electricity for one mile (kWh)

- Variables

$e_{u, t}^{\mathrm{EP}}$ : Energy supply by EP $u$ during period $t(\mathrm{kWh})$

$e_{v, t}^{\text {PHEV }}$ : Battery energy level of PHEV $v$ at the end of period $t$ $(\mathrm{kWh})$

$e_{v, t}^{+}, e_{v, t}^{-}$: Energy transferred to/from PHEV $v$ during period $t$ $(\mathrm{kWh})$

$x_{v, t}: 1$ if PHEV $v$ is charged during period $t, 0$ otherwise

$d_{v, t}^{\mathrm{CD}}, d_{v, t}^{\mathrm{CS}}$ : Travel distance in CD (charge-depleting) and CS (charge-sustaining) mode during period $t$ by PHEV $v$, respectively (miles)

$E_{v, t}^{\text {req }}$ : Required energy for PHEV $v$ during period $t(\mathrm{kWh})$

$\delta_{v, t}$ : DoD (Depth of Discharge) for PHEV $v$ during period $t$

$f(\delta)$ : Expected battery replacement cost as a function of DoD

$o_{u, t}, s_{u, t}, z_{u, t}: 1$ if EP $u$ is online, started up or shut down respectively in period $t, 0$ otherwise

$r_{v, t}$ : The cost variable of battery deterioration of PHEV $v$ at period

$t$, (used in battery degradation cost function modeling)

The cost minimization model is as follows:

$$
\begin{aligned}
\operatorname{minimize} \sum_{t \in T}[ & \sum_{u \in U} c_{u, t}^{\mathrm{EP}} \times e_{u, t}^{\mathrm{EP}}+\sum_{u \in U} c_{u}^{\mathrm{SU}} \times s_{u, t} \\
& \left.+\sum_{v \in V}\left(c_{t}^{\text {gas }} \times c s_{v} \times d_{v, t}^{\mathrm{CS}}+\left[f\left(\delta_{v, t}\right)-f\left(\delta_{v, t-1}\right)\right]^{+}\right)\right]
\end{aligned}
$$

subject to

$\underline{P}_{v} \leq e_{v, t}^{\mathrm{PHEV}} \leq \bar{P}_{v} ; \forall v \in V, \forall t \in T$

$e_{v, t}^{\mathrm{PHEV}}=e_{v, t-1}^{\mathrm{PHEV}}+\eta_{v}^{+} \times e_{v, t}^{+}-\frac{1}{\eta_{v}^{-}} \times e_{v, t}^{-}-E_{v, t}^{\mathrm{req}} ; \forall v \in V, \forall t \in T$

$e_{v, 0}^{\mathrm{PHEV}}=P 0_{v} ; \forall v \in V$

$e_{v, t}^{+} \leq \rho_{v}^{+} \times I_{v, t} \times x_{v, t} ; \forall v \in V, \forall t \in T$

$e_{v, t}^{-} \leq \rho_{v}^{-} \times I_{v, t} \times\left(1-x_{v, t}\right) ; \forall v \in V, \forall t \in T$

$d_{v, t}^{\mathrm{CD}} \leq d_{v, t}^{\mathrm{total}} ; \forall v \in V, \forall t \in T$

$d_{v, t}^{\mathrm{CD}} \leq \frac{\left(e_{v, t-1}^{\mathrm{PHEV}}-\underline{P}_{v}\right)}{E_{v}} ; \forall v \in V, \forall t \in T$

$d_{v, t}^{\mathrm{CS}}=d_{v, t}^{\mathrm{total}}-d_{v, t}^{\mathrm{CD}} ; \forall v \in V, \forall t \in T$

$E_{v, t}^{\mathrm{req}}=d_{v, t}^{\mathrm{CD}} \times E_{v} ; \forall v \in V, \forall t \in T$ $\delta_{v, t}=1-\frac{e_{v, t}^{\mathrm{PHEV}}}{\bar{P}_{v}} ; \forall v \in V, \forall t \in T$

$\sum_{u \in U} \eta_{u}^{\mathrm{EP}} \times e_{u, t}^{\mathrm{EP}}+\sum_{v \in V} e_{v, t}^{-}=\sum_{v \in V} e_{v, t}^{+}+l_{t}^{\mathrm{TIE}} ; \forall t \in T$

$o_{u, t} \times \underline{G}_{u, t} \leq e_{u, t}^{\mathrm{EP}} \leq o_{u, t} \times \bar{G}_{u, t} ; \forall u \in U, \forall t \in T$

$o_{u, t}-o_{u, t-1}=s_{u, t}+z_{u, t} ; \forall u \in U, \forall t \in T$

$\sum_{y=t-\tau_{u}^{+}} s_{u, y} \leq o_{u, t} ; \forall u \in U, \forall t \in T$

$\sum_{y=t-\tau_{\bar{u}}^{-}} z_{u, y} \leq 1-o_{u, t} ; \forall u \in U, \forall t \in T$

$x_{v, t}, o_{u, t}, s_{u, t}, z_{u, t} \in\{0,1\} ; \forall u \in U, \forall v \in V, \forall t \in T$

$e_{u, t}^{\mathrm{EP}}, e_{v, t}^{\mathrm{PHEV}}, e_{v, t}^{+}, e_{v, t}^{-}, E_{v, t}^{\mathrm{req}}, d_{v, t}^{\mathrm{CD}}, d_{v, t}^{\mathrm{CS}}, \delta_{v, t} \geq 0 ; \forall t \in T, \forall v \in V, \forall u \in U$

The objective function minimizes the cost of satisfying the residential loads and PHEV travel requirements. The cost components are: cost of energy generation, startup costs of EPs, gasoline prices and battery degradation cost which is a function of depth of discharge (DoD). Details of this function are presented in the following subsection. Constraints (2)-(11) are related to PHEVs. (2) enforces the minimum and maximum charge limits for each PHEV. (3) is the PHEV battery storage balance equation between periods. If the battery is charged (discharged), the stored energy level in the battery in the following period is increased (decreased) accordingly. (4) sets the initial battery level of each PHEV. (5) and (6) jointly ensure that charging and discharging do not occur simultaneously in each period and that either can only occur when the PHEV is connected to the grid. (7) and (8) together force the distance traveled in $\mathrm{CD}$ mode to be the minimum of the 'actual trip distance' and 'possible travel distance with the available energy left in the PHEV battery'. (9) sets the CS mode travel distance. (10) calculates the energy required to travel the trip distance and (11) calculates the DoD for each period. Constraints (12)-(16) are related to EPs. (12) is the energy balance equation. The sum of the total energy obtained from EPs and the discharged energy from the batteries equals the supplied energy for the PHEVs and the TIE loads. (13) ensures that the minimum and maximum capacities of each EP are met, and forces the binary variable $o_{u, t}$ to take value 1 if energy is generated by EP $u$ in period $t$. (14) sets the startup and shut down binary variables to correct values. Constraints (15) and (16) enforce the minimum and maximum up and down times of EPs. Finally, (17) defines the binary variables and (18) forces the non-negativity on the variables.

Theorem 1. In an optimal solution of the VPP Energy Management Model, simultaneous charging and discharging do not occur for any PHEV in any period when the binary variable $x_{v, t}$ is omitted from the formulation.

Proof. (By contradiction) Assume that charging and discharging simultaneously occur for PHEV $w$ during period $p$ in an optimal solution of the above formulation when the binary variable $x_{v, t}$ is omitted. Let $e_{w, p}^{+}=a>0$ and $e_{w, p}^{-}=b>0$. Then the VPP supplies $a$ units of energy for the PHEV $w$ and receives $b$ units of energy from the PHEV $w$. Therefore, the net energy generation required is $a-b$ units. On the other hand, due to the charging and discharging efficiencies of the 
PHEV $w$, it actually stores $\eta_{w}^{+} \times$a units of energy and loses $1 / \eta_{w}^{-} \times b$ units of energy back to the VPP. Then, the net energy stored in the PHEV $w$ battery is $c:=\eta_{w}^{+} \times a-\left(1 / \eta_{w}^{-}\right) \times b$. But $c$ units of energy could be directly provided by only charging $1 / \eta_{w}^{+} \times c$ units of energy, which is equal to $a-\left(1 / \eta_{w}^{+} \times \eta_{w}^{-}\right) \times b$. Since $\eta_{w}^{+}<1$ and $\eta_{w}^{-}<1$, we have $\left(1 / \eta_{w}^{+}\right) \times c<a-b$. Thus, the same level of storage for the battery of PHEV $w$ during period $p$ could be achieved by generating less energy, which means less cost. This contradicts that the solution with simultaneous charging and discharging is the optimal (i.e., the least-cost) solution.

In other words, because the batteries are not $100 \%$ efficient when charging or discharging, it is less costly to charge the required energy directly rather than first charging more energy and then discharging the batteries. Note the non-restrictive underlying assumption that the more energy obtained from EPs, the more cost the VPP incurs. As a result of this theorem, binary variable $x_{v, t}$ can be omitted from the energy management model.

Solving the above model gives the least cost that can be achieved by the VPP. Observe that if we solve the model for only a given vehicle $v$ by taking into account the grid as the single EP, then we obtain the least cost of this PHEV for traveling the desired trip mileage if it was in the national grid domain.

\subsection{Modeling the battery degradation cost}

In order to model the battery degradation cost, we follow a similar methodology to that of Sioshansi and Denholm [40]. The battery of the PHEV has a limited lifespan and it deteriorates through usage. Therefore discharging or depleting the battery shortens its life; and after enough many times, the battery needs to be replaced. Therefore the VPP incurs a cost each time a battery is used. The lifetime of a PHEV battery is inversely proportional with the DoD [41] as shown in Fig. 2.

Therefore, the more the energy is discharged, the less the lifespan of the battery is; and this implies more cost for deeper discharging. The nonlinearity in the battery deterioration cost as a function of DoD can be approximated with a piecewise linear function. An example battery degradation function for a battery that costs $\$ 4189$ is depicted in Fig. 3. Approximations by a linear function and a 2-piece piecewise linear function are also depicted in this figure.

To handle the linearization of the battery degradation cost function, we adopted the methodology presented in Nemhauser and Wolsey [42]. Consider a piecewise linear function with $K$ pieces and let $a_{v}^{i}$ be the DoD values at the break points, and $f\left(a_{v}^{i}\right)$ be the function values evaluated at each $a_{v}^{i}$ for $i \in\{1, \ldots, K\}$. Let $r_{v, t}=\left[f\left(\delta_{v, t}\right)-f\left(\delta_{v, t-1}\right)\right]^{+}$be the cost variable of battery deterioration of PHEV $v$ at period $t$; and $\lambda_{v, t}^{i}$ and $y_{v, t}$ be the auxiliary variables used

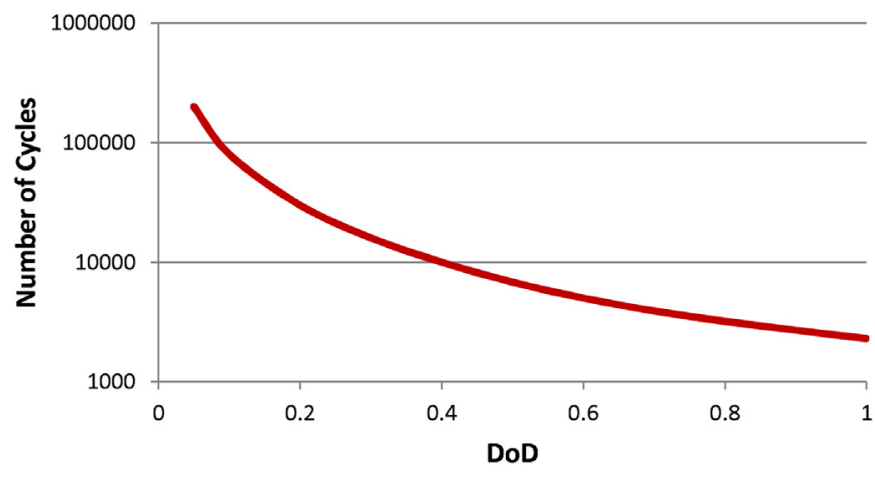

Fig. 2. Cycle life of PHEV batteries as a function of DoD.

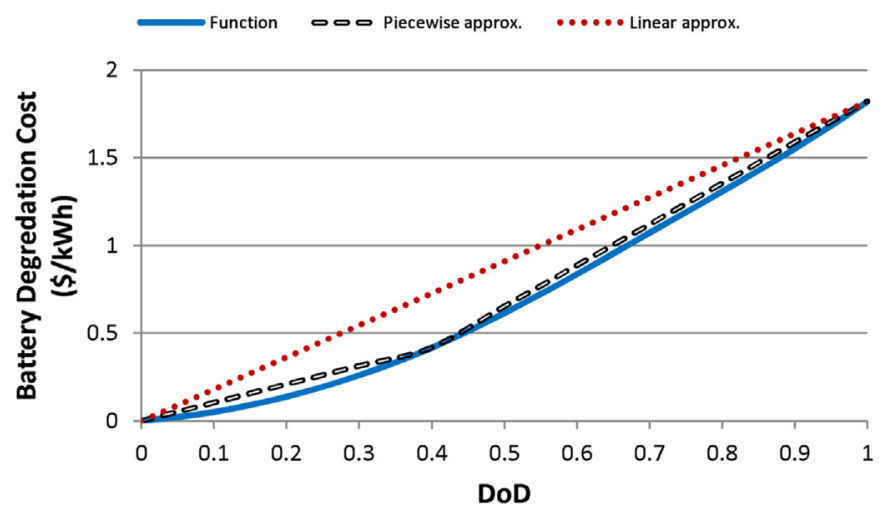

Fig. 3. Battery degradation cost function and approximating functions.

in linearization. Then, in order to deal with $\left[f\left(\delta_{v, t}\right)-f\left(\delta_{v, t-1}\right)\right]^{+}$term, we incorporate the following integer linear program into our model:

$\operatorname{minimize} \sum_{t \in T} \sum_{v \in V} r_{v, t}$

subject to

$$
\begin{aligned}
& r_{v, t} \geq \sum_{i=1}^{K} \lambda_{v, t}^{i} \times f\left(a_{v}^{i}\right)-\sum_{i=1}^{K} \lambda_{v, t-1}^{i} \times f\left(a_{v}^{i}\right) ; \forall v \in V, \forall t \in T \\
& r_{v, t} \geq 0 ; \forall v \in V, \forall t \in T
\end{aligned}
$$

$\delta_{v, t}=\sum_{i=1}^{K} \lambda_{v, t}^{i} \times a_{v}^{i} ; \forall v \in V, \forall t \in T$

$\lambda_{v, t}^{1} \leq y_{v, t}^{1} ; \forall v \in V, \forall t \in T$

$\lambda_{v, t}^{i} \leq y_{v, t}^{i}+y_{v, t}^{i-1} ; \forall v \in V, \forall t \in T, i=2, \ldots, K-1$

$\lambda_{v, t}^{K} \leq y_{v, t}^{K-1} ; \forall v \in V, \forall t \in T$

$$
\sum_{i=1}^{K} \lambda_{v, t}^{i}=1 ; \forall v \in V, \forall t \in T
$$

$\sum_{i=1}^{K-1} y_{v, t}^{i}=1 ; \forall v \in V, \forall t \in T$

$\lambda_{v, t}^{i} \geq 0 ; \forall v \in V, \forall t \in T$

$y_{v, t}^{i} \in\{0,1\} ; \forall v \in V, \forall t \in T, i=1, \ldots, K-1$

If $\sum_{t \in T} \sum_{v \in V}\left[f\left(\delta_{v, t}\right)-f\left(\delta_{v, t-1}\right)\right]^{+}$term in the objective function of the VPP energy management model is replaced with $\sum_{t \in T} \sum_{v \in V} r_{v, t}$, and constraints (20)-(29) are appended to (2)-(18), we obtain an MILP for the energy management problem. The higher the number of the pieces, the better the approximation is of the nonlinear form. 


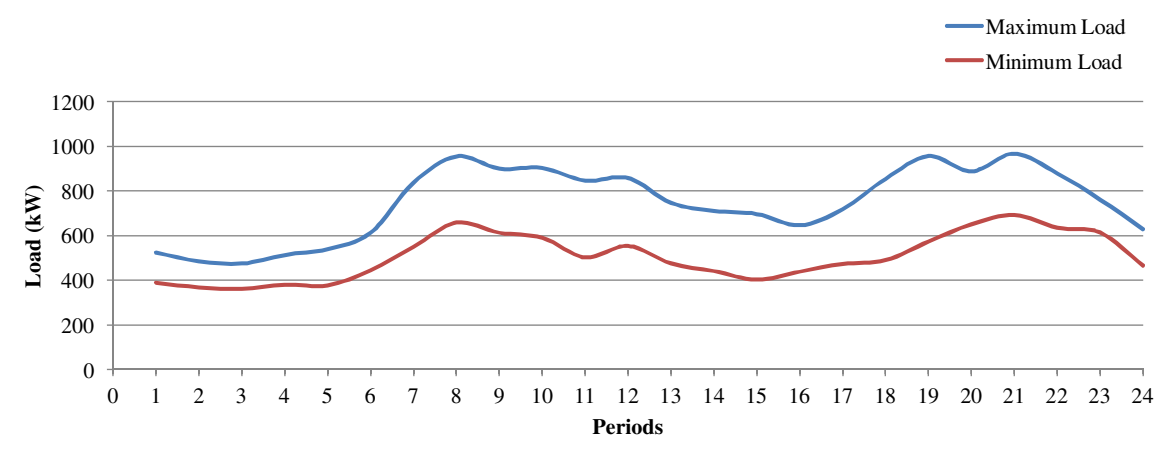

Fig. 4. Hourly maximum and minimum TIE load data.

\section{Case study}

Our research aim is to analyze the cost and emission impacts of VPP formation in PHEV-penetrated networks. In order to achieve this goal, we consider a group of people forming a VPP in the state of California. We compare the cost and emission values to the case when the group members obtain energy from the national grid with respect to the individually optimized tariffs. This way, we are able to measure the value of VPP formation. Furthermore, we consider the VPP formation with and without PHEVs so that we evaluate the value of PHEVs in this formation. We also carry out sensitivity analyses on the gasoline prices, battery prices, energy prices and generation capacities.

\subsection{Data}

We gathered travel patterns, electricity consumption and pricing data for the state of California. The travel data is based on the US Department of Transportation's National Household Travel Survey [43]. We include 26,408 trips, made by 213 compact cars, mid-size cars, large cars and small SUVs in an urban area in the case study. Using this data, we study a hypothetical VPP that serves 574 houses with 213 PHEVs. The data is regarded as a representation of driving patterns for 30 generic days, which accounts to 4.132 different trips daily for each PHEV. The gasoline prices for 30 days are assumed to vary between $\$ 3.037$ and $\$ 3.059$. Actual trip distances $\left(d_{v, t}^{\text {total }}\right)$ are extracted from the trip data. We assume that all PHEVs and houses are in the VPP's area of responsibility and that the electricity demand of the houses and PHEVs is controlled by the VPP.

Hourly electricity demand per household for TIE loads is obtained from Pacific Gas and Electric Company (PG\&E) [44] for 30 days. Hourly TIE load data is multiplied by 574 to obtain the TIE load data $\left(l_{t}^{\mathrm{TIE}}\right)$. The hourly TIE load for each of the 30 days changes between the minimum and maximum limits, as shown in Fig. 4. The peak power is $0.967 \mathrm{MW}$.

A day is represented by 24 hourly periods. Similar to previous studies, including [38], PHEVs that are available for a whole hour are regarded as available for charging, and $I_{v, t}$ is set to 1 . Average number of PHEVs on road for each time period is shown in Fig. 5.
Table 1 lists the energy requirements per mile $\left(E_{v}\right)$, battery capacities $\left(\bar{P}_{v}\right)$, battery costs, and the mileage that can be traveled per gallon of gasoline (MPG) in CS mode for each type of vehicle. $E_{v}$ values are estimated by the Pacific Northwest National Laboratory [45]. We calculate the average gasoline usage of a PHEV $\left(\operatorname{cs}_{v}\right)$ as the reciprocal of MPG. The minimum battery storage level $\left(\underline{P}_{v}\right)$ and the initial energy stored in batteries $\left(P O_{v}\right)$ are assumed to be $10 \%$ and $30 \%$ of their capacities, respectively. Charging and discharging efficiencies of the batteries $\left(\eta_{v}^{+}\right.$and $\left.\eta_{v}^{-}\right)$are $90 \%$. The charge and discharge limits per period $\left(\rho_{v}^{+}\right.$and $\rho_{v}^{-}$) are taken as $2.4 \mathrm{~kW}$ for all PHEVs.

The battery costs shown in Table 1 are estimated using the BatPaC $2.1^{\odot}$ tool by Argonne National Laboratory [46] and they are used to estimate the expected battery replacement cost function $(f(\delta))$ of the batteries. At this point, we note that the expected battery replacement cost functions for each vehicle type for the DoD values between 0 and 1 can be approximated by a single linear function or 2-piece linear function (See Fig. 3). Solving our model for 30 days with both linear and piecewise linear models, we observe no statistically significant differences in results, but longer solution times for piecewise linear models. Thus, we assume a linear model in the subsequent experimentations in this study.

Thirty-four EPs are included in the case study. The data pertaining to EPs is extracted from the California Energy Comission DER Guide [47] and the Comparative Costs of California Central Station Electricity Generation Report [48] and is shown in Table 2 $\left(\bar{G}_{u, t}, c_{u, t}^{\mathrm{EP}}\right.$ and $\left.\eta_{u}^{\mathrm{EP}}\right)$. For simplicity of the presentation, the minimum and maximum limits of all EPs are assumed to be time invariant. However, our model is capable of handling time-variant data provided that proper data is attainable. The minimum limit $\left(\underline{G}_{u, t}\right)$ is assumed to be $5 \mathrm{kWh}$ for all EPs, and the minimum up and down times are assumed to be one period for each EP. The VPP can also obtain energy from the national grid if the capacity of the existing EPs is not enough to satisfy the demand load. The startup costs for non-dispatchable units such as wind turbines are simply zero. We assume that the startup cost for dispatchable EPs is the cost of running the unit at full power for an hour.

We consider 4 different residential tariff structures of PG\&E [49]: E1, E6, E7 and E9, from which the consumers can select if they individually obtain energy from the national grid. The tariff

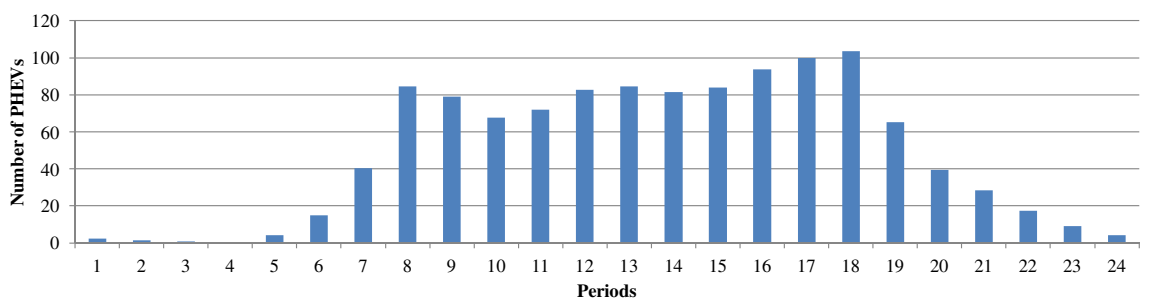

Fig. 5. Average number of PHEVs on road versus time periods. 
Table 1

Vehicle type specifications.

\begin{tabular}{lllll}
\hline Vehicle class & $\begin{array}{l}\text { Energy requirement } \\
{[\mathrm{kWh} / \mathrm{mile}]}\end{array}$ & $\begin{array}{l}\text { Battery capacity } \\
{[\mathrm{kWh}]}\end{array}$ & $\begin{array}{l}\text { Battery } \\
\text { cost [\$] }\end{array}$ & $\begin{array}{l}\text { MPG in } \\
\text { CS-mode }\end{array}$ \\
\hline Compact & 0.26 & 8.6 & 3178 & 30.2 \\
Mid-size & 0.30 & 9.9 & 3377 & 26.4 \\
Large & 0.38 & 12.5 & 3776 & 20.6 \\
Small SUV & 0.46 & 15.2 & 4189 & 18 \\
\hline
\end{tabular}

Table 2

EP data.

\begin{tabular}{lllrl}
\hline DER type & $\begin{array}{l}\text { Number } \\
\text { of units }\end{array}$ & $\begin{array}{l}\text { Maximum } \\
\text { limit [kWh] }\end{array}$ & Price [đ/kWh] & EP efficiency [\%] \\
\hline Microturbine & 2 & 50 & 24.43 & 95.8 \\
Photovoltaics & 7 & 25 & 26.22 & 76.0 \\
Wind turbine & 8 & 50 & 7.24 & 99.9 \\
Biomass & 5 & 28 & 10.83 & 93.0 \\
Fuel cell & 3 & 50 & 26.65 & 85.0 \\
Small hydro & 5 & 15 & 8.65 & 87.0 \\
Geothermal & 4 & 15 & 8.31 & 90.0 \\
\hline
\end{tabular}

structures are presented in Fig. 6. E1 is a fixed pricing throughout the day, E6, E7 and E9 are different ToU (time-of-use) tariffs, in which consumers are charged with respect to the time of the day.

Conventional (gasoline powered) vehicles and EPs emit nitrogen oxides $\left(\mathrm{NO}_{x}\right)$ and carbon dioxide $\left(\mathrm{CO}_{2}\right)$, both of which are hazardous to human health and detrimental to nature. The $\mathrm{CO}_{2}$ and $\mathrm{NO}_{x}$ emission data in Table 3 is obtained from U.S. DOE EERE (Energy Efficiency and Renewable Energy) [50,51] and U.S. Environmental Protection Agency [52]. Photovoltaics, wind turbine, small hydro and geothermal are assumed to have insignificant/zero amounts of emission.

We solve the VPP Energy Scheduling Model with different settings. The model under consideration has 60,125 (2625 binary) variables and 118,486 constraints. We solve the models using IBM's ILOG CPLEX 12.5 Optimization Studio ${ }^{\circledR}$ on a computer with $2.00 \mathrm{GHz}$ dual-core processor and 2.00 GB RAM.

\subsection{Value of VPP and PHEVs}

We consider 5 scenarios presented in Table 4 . In the 1 st scenario, all of the vehicles are considered to be running on gasoline, and the grid supplies energy for the residential loads. The consumers choose one of the following tariffs individually: E1, E6, E7, or E9. We assume that they behave rationally and select the tariff that gives the least cost. In the 2nd scenario, the vehicles again run on gasoline; but this time, the VPP manages the energy to minimize the total cost. For each of the scenarios, we run the optimization model for 30 times with individualized data pertaining to daily residential loads and driving profiles. The reported cost and emission values are the averages of these 30 runs. The daily average cost in grid domain is $\$ 2720.4$, which amounts to an average of $\$ 142.1$ monthly bill per house. The average cost in the VPP domain reduces to $\$ 2045.8$ and
Table 3

Emission data.

\begin{tabular}{lcll}
\hline Technology & $\mathrm{CO}_{2}$ & $\mathrm{NO}_{x}$ & Unit \\
\hline Microturbine & 539.8 & 0.2223 & grams $/ \mathrm{kWh}$ \\
Biomass & 0 & 0.034 & \\
Fuel Cell & 385.6 & 0.0068 & \\
Grid (average) & 544.3 & 2.267 & \\
Compact car & 291.0 & 0.07 & grams/mile (in CS mode) \\
Mid-size car & 335.0 & 0.07 & \\
Large car & 395.0 & 0.07 & \\
Small SUV & 480.0 & 0.07 & \\
\hline
\end{tabular}

the cost saving of VPP formation is $\$ 674.6$ per day; in other words, an average of $\$ 35$ saving per house in the monthly bill. Even though both scenarios supply the same level of energy for the residential loads, the emission reduction is also drastic when the VPP is formed, because of the fact that the average emission values of the grid are much higher than those of renewable energy resources.

When the PHEVs are introduced in 3rd and 4th scenarios, cost reduction is attained in both domains, but the cost reduction is less in grid domain. Daily average cost savings of VPP formation with respect to grid in PHEV-penetrated network is $\$ 774.4$, an average of $29.5 \%$ cost reduction. This amounts to $\$ 40.5$ reduction in the monthly bill. Emission is again much less in the VPP domain when compared with the grid domain. $79 \% \mathrm{CO}_{2}$ and $83 \% \mathrm{NO}_{x}$ emission reductions are attained as shared benefits of consumers in PHEVpenetrated networks.

PHEVs are running on electricity rather than gasoline in 3rd and 4th scenarios. Hence, the electricity generation increases with respect to 1 st and 2nd scenarios. Because average electricity generation $\mathrm{NO}_{x}$ emission is higher than the PHEV $\mathrm{NO}_{x}$ emission (see Table 3), $\mathrm{NO}_{x}$ emission is increasing in both domains when PHEVs are introduced to the network. Note that $\mathrm{CO}_{2}$ reduces in both VPP and grid domains when PHEVs are introduced into the network.

Besides VPP and PHEVs, we also include the V2G (Vehicle-togrid) capability of the PHEV in the 5th scenario (Actually the technology is Vehicle-to-VPP in our case). Observe that the cost reduction is not statistically significant. This is because the electricity cost reduction due to discharging is neutralized by the increase in the battery degradation cost. Refer to Table A.1 in the Appendix for the breakdown of cost, distance and emission values. The energy generation is slightly more in the 5th scenario with respect to the 4 th scenario due to charge and discharge cycles and therefore the emissions increase with V2G accordingly. Though cost and emission gains seem to be insignificant, Sioshansi and Denholm [40] show that the spinning reserve cost reduction can be very rewarding in the grid domain when V2G capability is included.

\subsection{Sensitivity to gasoline prices}

In scenarios $6-10$, the gasoline price changes between $\$ 1.5$ and $\$ 4.0$. Even though the cost values in Table 5 change almost linearly with the gasoline prices, the three cost components in Table A.1

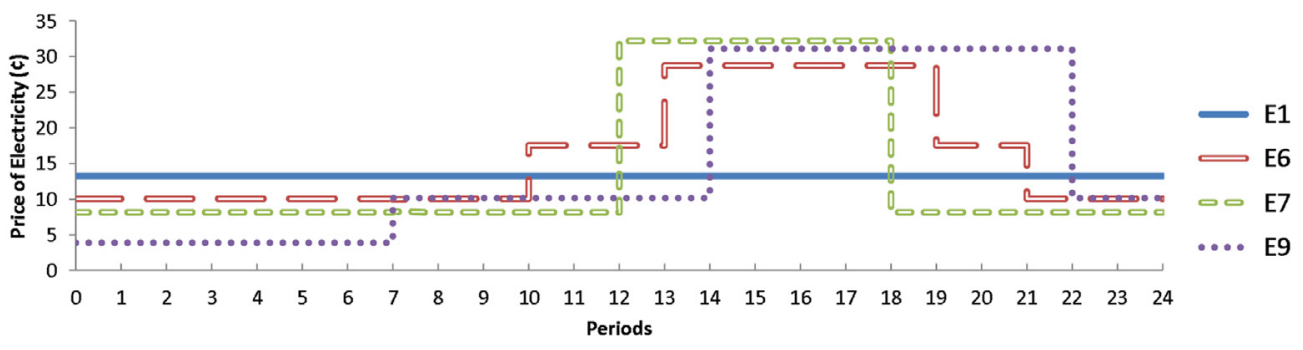

Fig. 6. E1, E6, E7 and E9 tariffs of PG\&E. 
Table 4

Daily average cost and emission comparison of VPP and the grid.

\begin{tabular}{lllllrc}
\hline Scenario \# & Domain & PHEV & V2G & Cost $[\$]$ & $\mathrm{CO}_{2}[\mathrm{~kg}]$ & $\mathrm{NO}_{x}[\mathrm{~kg}]$ \\
\hline 1 & Grid & - & - & 2720.4 & 10226.8 & 33.6 \\
2 & VPP & - & - & 2045.8 & 3217.7 & 4.5 \\
3 & Grid & + & - & 2628.7 & 9648.2 & 38.0 \\
4 & VPP & + & - & 1854.3 & 2031.3 & 6.3 \\
5 & VPP & + & + & 1850.7 & 2042.4 & 6.4 \\
\hline
\end{tabular}

react differently. As gasoline prices increase from $\$ 1.5$ to $\$ 4.0$, the gasoline cost decreases from $\$ 386.6$ to $\$ 246.8$, the electricity cost increases from $\$ 1238.6$ to $\$ 1418.4$ and the battery degradation cost increases from $\$ 15.4$ to $\$ 244.9$. The reason is that when the gasoline prices increase, the PHEV owners prefer to travel more on the $C D$ mode. Observe that the decrease in gasoline cost cannot compensate for the electricity and battery cost increases. Therefore, the cost increases as gasoline prices increase.

The CD mode distances in 6th and 7th scenarios in Table A.1 are much less than the distances in 8th, 9th and 10th scenarios. Observe that there is a break-even price between $\$ 2.0$ and $\$ 2.5$. For gasoline costs higher than the break-even price, $C D$ mode driving is more profitable than CS mode driving in almost every trip. Note that this break-even price is specific only for this scenario and would change in different combination of EPs and/or PHEVs.

\subsection{Sensitivity to battery prices}

In scenarios $11-14$, we analyze the effect of the battery price change (Table 6). In the 11th scenario, the battery prices for each PHEV type are as presented in Table 1 . In the 12th and 13th scenarios, we assume a price reduction of $\$ 1000$ and $\$ 2000$ for each PHEV battery, respectively. In the 14 th scenario, we simply do not consider the battery prices to see how the results are affected.

In the 12th and 13th scenarios, we benefit \$69.1 and \$139.3 battery degradation cost reduction with respect to the 11 th scenario, which amounts to $\$ 9.7$ and $\$ 19.6$ monthly cost reduction per PHEV. Note that the trip distances on CD and CS modes in 13th and 14th scenarios are exactly the same in Table A.1. Therefore one would expect that the electricity generation costs need to be the same, since the electricity requirements for both $\mathrm{CD}$ mode traveling and residential loads are the same. But the electricity costs are not the same as seen in Table A.1. The reason is that, the battery has no cost in the 14th scenario. Therefore discharging occurs more and this creates cost savings.

\subsection{Sensitivity to energy prices}

In the 15th, 16th and 17th scenarios, we consider different EP prices. 15th scenario uses the pricing data presented in Table 2.16th and 17th scenarios assume half and one third of these prices for each EP (excluding the grid), respectively. Results in Table 7 show that the VPP obtains the energy for cheaper with decreasing prices, as expected. Note that the 15th and 16th scenarios have almost identical CD mileages in Table A.1. Thus, similar levels of electricity

Table 5

Sensitivity of daily average cost and emission to gasoline prices.

\begin{tabular}{lllll}
\hline Scenario \# & Gas price $[\$]$ & Cost $[\$]$ & $\mathrm{CO}_{2}[\mathrm{~kg}]$ & $\mathrm{NO}_{x}[\mathrm{~kg}]$ \\
\hline 6 & 1.5 & 1640.6 & 3155.9 & 4.2 \\
7 & 2.0 & 1764.7 & 2857.5 & 4.3 \\
8 & 2.5 & 1815.1 & 2058.4 & 6.3 \\
9 & 3.0 & 1850.7 & 2042.4 & 6.4 \\
10 & 4.0 & 1910.0 & 2038.5 & 6.4 \\
\hline
\end{tabular}

Table 6

Sensitivity of daily average cost and emission to battery prices.

\begin{tabular}{lllll}
\hline Scenario \# & Battery price change $[\$]$ & Cost $[\$]$ & $\mathrm{CO}_{2}[\mathrm{~kg}]$ & $\mathrm{NO}_{x}[\mathrm{~kg}]$ \\
\hline 11 & 0 (as is) & 1850.7 & 2042.6 & 6.4 \\
12 & -1000 & 1781.6 & 2041.0 & 6.4 \\
13 & -2000 & 1711.4 & 2042.2 & 6.4 \\
14 & No battery cost & 1586.0 & 2221.0 & 7.1 \\
\hline
\end{tabular}

Table 7

Sensitivity of daily average cost and emission to DER prices.

\begin{tabular}{lllll}
\hline Scenario \# & DER price change [\$] & Cost [\$] & $\mathrm{CO}_{2}[\mathrm{~kg}]$ & $\mathrm{NO}_{x}[\mathrm{~kg}]$ \\
\hline 15 & $\times 1$ & 1850.7 & 2042.4 & 6.4 \\
16 & $\times 1 / 2$ & 1208.8 & 1132.1 & 1.7 \\
17 & $\times 1 / 3$ & 958.5 & 1166.0 & 0.8 \\
\hline
\end{tabular}

are generated in both scenarios. However, the emission values differ significantly. The reason is that when the prices decrease, more renewable EPs are used to generate the electricity, and the emissions reduce accordingly.

\subsection{Sensitivity to generation capacity}

In this analysis, we consider doubling the EP capacities that are presented in Table 2 . In the 19th scenario, capacity expansion results in more DERs being used to generate the required energy (Table 8). Thus the cost as well as emissions reduce accordingly. When there is enough capacity of renewable EPs to satisfy the demand load, the emission due to generation decreases to insignificant amounts, virtually zero as it is in the 19th scenario (see Table A.1).

\subsection{Sensitivity to hourly energy availability}

Though in our illustrative example, we took generation limits as time-invariant, in reality, photovoltaics and wind turbines are technologies which by nature have limitations throughout the day. In the 20th scenario, the wind follows a forecasted distribution within the day and photovoltaics are available depending on the sun angle over the horizon. We have obtained the distribution of production by photovoltaics and wind turbines from CAISO Renewables Watch [53]. The photovoltaics generate electricity from 7 a.m. until 7 p.m. peaking at noon and the average generation is $25 \mathrm{kWh}$. The wind generate energy throughout the day peaking at midnight and the average generation is $50 \mathrm{kWh}$. Solving the energy management model for 30 days, the average daily cost is $\$ 1868.62$, the average $\mathrm{CO}_{2}$ and $\mathrm{NO}_{x}$ emissions are $1931.33 \mathrm{~kg}$ and $5.84 \mathrm{~kg}$, respectively. With current settings, the cost increases from the VPP scenario with V2G capability (5th scenario) by $\$ 25.75$ and average $\mathrm{CO}_{2}$ and $\mathrm{NO}_{x}$ emissions decrease by $111.07 \mathrm{~kg}$ and $0.46 \mathrm{~kg}$, respectively. The increase in cost is due to the fact that wind turbines generate less electricity in peak times and energy is provided from more expensive resources instead. On the other hand, the discharging occurs more in peak times in order to compensate for the energy production reduction by wind turbines. This, in turn, reduce the emissions, since discharging leads to less energy being generated.

Table 8

Sensitivity of daily average cost and emission to DER total capacity.

\begin{tabular}{lllrl}
\hline Scenario \# & DER capacity change [\$] & Cost $[\$]$ & $\mathrm{CO}_{2}[\mathrm{~kg}]$ & $\mathrm{NO}_{x}[\mathrm{~kg}]$ \\
\hline 18 & $\times 1$ & 1850.7 & 2042.4 & 6.4 \\
19 & $\times 2$ & 1606.6 & 542.6 & 1.1 \\
\hline
\end{tabular}




\section{Conclusions}

In this study, we consider a group of people forming a VPP in a PHEV-penetrated electricity network in order to reduce total electricity spendings through economies of scale. We assume that the VPP obtains energy from several renewable energy resources. To compare the cases with and without VPP and/or PHEVs, we first developed a new model that schedules the dispatch of EPs and the charging and discharging of PHEV batteries. Solving the model for several different settings, we obtained insightful results.

First and the foremost, this article highlights the cost and emission benefits of VPP formation and PHEV penetration into the network. Additionally, sensitivity of these benefits to different changes in the system is analyzed. The results show that the benefits of VPP formation can flourish if energy generation costs of renewable energy resources decrease or the capacities of the contracted EPs increase. For the scenarios considered in this paper, an average of $29.5 \%$ cost reduction and $79 \% \mathrm{CO}_{2}$ and $83 \% \mathrm{NO}_{x}$ emission reductions are attained as shared benefits of consumers in PHEV- the VPP. Even though we have shown the cost reduction of VPP formation, how to share this cost reduction fairly among the parties can further be investigated.

\section{Acknowledgments}

We are thankful to two anonymous referees for constructive feedbacks in leading to the current form of this article.

\section{Appendix A. Daily average distance, cost and emission breakdowns}

Table A.1 lists daily average distance, cost and emission breakdowns for the 20 scenarios considered in this article. The daily average trip distance, 6463.6 miles for each scenario, is traveled either in CS or CD mode. The cost values correspond to the total of battery deterioration cost, electricity cost and gasoline cost. The emissions are categorized by the source: tailpipe emissions (T.P.) and emissions due to electricity generation by EPs (Gen.).

Table A.1

Daily average generation, distance, cost and emission breakdowns

\begin{tabular}{|c|c|c|c|c|c|c|c|c|c|c|}
\hline \multirow[t]{2}{*}{ Scn. \# } & \multirow[t]{2}{*}{ Generation [MW] } & \multicolumn{2}{|c|}{ Distance [miles] } & \multicolumn{3}{|c|}{ Costs $[\$]$} & \multicolumn{2}{|c|}{$\mathrm{CO}_{2}[\mathrm{~kg}]$} & \multicolumn{2}{|c|}{$\mathrm{NO}_{x}[\mathrm{~kg}]$} \\
\hline & & $C D$ & CS & Bat. & Elec. & Gas. & T.P. & Gen. & T.P. & Gen. \\
\hline 1 & 14.92 & 0 & 6463.5 & 0 & 1934.3 & 786.1 & 2268.7 & 7958.2 & 0.5 & 33.2 \\
\hline 2 & 15.04 & 0 & 6463.5 & 0 & 1259.6 & 786.1 & 2268.7 & 949.0 & 0.5 & 4.0 \\
\hline 3 & 16.73 & 4956.5 & 1507.0 & 227.5 & 2213.2 & 188.0 & 542.6 & 9105.6 & 0.1 & 37.9 \\
\hline 4 & 16.92 & 4923.4 & 1540.2 & 226.0 & 1436.4 & 191.9 & 554 & 1477.4 & 0.1 & 6.2 \\
\hline 5 & 16.95 & 4922.9 & 1540.6 & 241.8 & 1416.9 & 192.0 & 554.2 & 1488.2 & 0.1 & 6.2 \\
\hline 6 & 15.08 & 1.1 & 6462.5 & 15.4 & 1238.6 & 386.6 & 2268.3 & 887.5 & 0.5 & 3.7 \\
\hline 7 & 15.47 & 713.1 & 5750.4 & 54.1 & 1272.3 & 438.3 & 1934.4 & 923.1 & 0.4 & 3.9 \\
\hline 8 & 16.91 & 4813.6 & 1649.9 & 236.8 & 1410.3 & 168.0 & 591.5 & 1466.9 & 0.1 & 6.2 \\
\hline 9 & 16.95 & 4922.9 & 1540.6 & 241.8 & 1416.9 & 192.0 & 554.2 & 1488.2 & 0.1 & 6.2 \\
\hline 10 & 16.96 & 4955.3 & 1508.2 & 244.9 & 1418.4 & 246.8 & 543 & 1495.4 & 0.1 & 6.3 \\
\hline 11 & 16.95 & 4922.9 & 1540.6 & 241.8 & 1416.9 & 192.0 & 554.2 & 1488.2 & 0.1 & 6.2 \\
\hline 12 & 16.96 & 4954.0 & 1509.5 & 175.0 & 1418.2 & 188.3 & 543.6 & 1497.5 & 0.1 & 6.3 \\
\hline 13 & 16.96 & 4956.5 & 1507.0 & 105.1 & 1418.3 & 188.0 & 542.6 & 1499.6 & 0.1 & 6.3 \\
\hline 14 & 17.08 & 4956.5 & 1507.0 & 0 & 1398.0 & 188.0 & 542.6 & 1678.4 & 0.1 & 7 \\
\hline 15 & 16.95 & 4922.9 & 1540.6 & 241.8 & 1416.9 & 192.0 & 554.2 & 1488.2 & 0.1 & 6.2 \\
\hline 16 & 22.78 & 4955.9 & 1507.6 & 227.8 & 792.8 & 188.1 & 542.8 & 589.3 & 0.1 & 1.6 \\
\hline 17 & 22.75 & 4956.5 & 1507.0 & 227.5 & 543.0 & 188.0 & 542.6 & 623.4 & 0.1 & 0.7 \\
\hline 18 & 16.95 & 4922.9 & 1540.6 & 241.8 & 1416.9 & 192.0 & 554.2 & 1488.2 & 0.1 & 6.2 \\
\hline 19 & 22.75 & 4956.3 & 1507.3 & 227.5 & 1191.1 & 188.0 & 542.7 & 0 & 0.1 & 0 \\
\hline 20 & 16.95 & 4887.6 & 1575.9 & 249.5 & 1422.9 & 196.3 & 566.5 & 1233.5 & 0.1 & 5.2 \\
\hline
\end{tabular}

penetrated networks. The benefits of VPP formation are even more significant when PHEV battery costs decrease and uncertainty in gasoline prices persists. Results are illustrative of opportunities that VPP formation can provide for the community.

In addition, we theoretically show that charging and discharging do not simultaneously occur in the solutions and hence the binary variables that are traditionally included in energy management models can be excluded.

There are several tough challenges that the electricity market needs to tackle in the near future including volatile prices, threats of supply shortages and capacity expansion requirements of the regular electricity grid with increasing population. In the meantime, there are some real world applications of VPPs emerging all around the world [3], which could be a fundamental solution to these challenges. Together with the cost and emission benefits presented in this study, we expect that the upward trend towards VPPs will continue, especially with the introduction of new technologies such as Smart Grid.

As possible future research areas, the uncertainties associated with the whole system can be taken into account for more robust schedules. Also we assumed no pricing between the consumers and

\section{References}

[1] Asmus P. Microgrids, virtual power plants and our distributed energy future. Electricity J 2010;23(10):72-82.

[2] Fang X, Misra S, Xue G, Yang D. Smart grid-the new and improved power grid: a survey. IEEE Commun Surv Tutor 2011;14(4):944-80.

[3] Nikonowicz LB, Milewski J. Virtual power plants general review: structure, application and optimization. J Power Tech 2012;92(3):135-49.

[4] Morais H, Kàdàr P, Faria P, Vale ZA, Khodr H. Optimal scheduling of a renewable micro-grid in an isolated load area using mixed-integer linear programming. Renew Energy 2010:35(1):151-6.

[5] Khodr H, Halabi NE, García-Gracia M. Intelligent renewable microgrid scheduling controlled by a virtual power producer: a laboratory experience. Renew Energy 2012;48:269-75.

[6] Kriett PO, Salani M. Optimal control of a residential microgrid. Energy 2012;42(1):321-30.

[7] Naraharisetti PK, Karimi I, Anand A, Lee DY. A linear diversity constraintapplication to scheduling in microgrids. Energy 2011:36(7):4235-43.

[8] Moghaddam AA, Seifi A, Niknam T, Pahlavani MRA. Multi-objective operation management of a renewable MG (micro-grid) with back-up micro-turbine/ fuel cell/battery hybrid power source. Energy 2011;36(11):6490-507.

[9] Basu AK, Chowdhury S, Chowdhury S, Paul S. Microgrids: energy management by strategic deployment of DERs-a comprehensive survey. Renew Sust Energ Rev 2011;15(9):4348-56.

[10] Xiong G, Chen C, Kishore S, Yener A. Smart (in-home) power scheduling for demand response on the smart grid. In: Innovative smart grid technologies (ISGT), IEEE PES 2011. p. 1-7. 
[11] Pedrasa MAA, Spooner TD, MacGill IF. A novel energy service model and optimal scheduling algorithm for residential distributed energy resources. Electr Power Syst Res 2011;81(12):2155-63.

[12] Rastegar M, Fotuhi-Firuzabad M, Aminifar F. Load commitment in a smart home. Appl Energy 2012;96:45-54.

[13] Elma O, Selamogullari US. A comparative sizing analysis of a renewable energy supplied stand-alone house considering both demand side and source side dynamics. Appl Energy 2012;96:400-8.

[14] Mehleri ED, Sarimveis H, Markatos NC, Papageorgiou LG. A mathematical programming approach for optimal design of distributed energy systems at the neighbourhood level. Energy 2012;44(1):96-104.

[15] Alagoz B, Kaygusuz A, Karabiber A. A user-mode distributed energy management architecture for smart grid applications. Energy 2012;44(1):167-77.

[16] Siddiqui AS, Marnay C. Distributed generation investment by a microgrid under uncertainty. Energy 2008;33(12):1729-37.

[17] Doagou-Mojarrad H, Gharehpetian G, Rastegar H, Olamaei J. Optimal placement and sizing of $\{D G\}$ (distributed generation) units in distribution networks by novel hybrid evolutionary algorithm. Energy 2013;54(0):129-38.

[18] Kuznetsova E, Li YF, Ruiz C, Zio E, Ault G, Bell K. Reinforcement learning for microgrid energy management. Energy 2013;59:133-46.

[19] Mitra S, Sun L, Grossmann IE. Optimal scheduling of industrial combined heat and power plants under time-sensitive electricity prices. Energy 2013;54(0): 194-211.

[20] Kusch W, Schmidla T, Stadler I. Consequences for district heating and natural gas grids when aiming towards $100 \%$ electricity supply with renewables. Energy 2012;48(1):153-9.

[21] Panto M. Stochastic optimal charging of electric-drive vehicles with renewable energy. Energy 2011;36(11):6567-76.

[22] Fernandes C, Frías P, Latorre JM. Impact of vehicle-to-grid on power system operation costs: the Spanish case study. Appl Energy 2012;96:194-202.

[23] Saber A, Venayagamoorthy G. Resource scheduling under uncertainty in a smart grid with renewables and plug-in vehicles. IEEE Syst J 2012;6(1):103-9.

[24] Kristoffersen TK, Capion K, Meibom P. Optimal charging of electric drive vehicles in a market environment. Appl Energy 2011;88(5):1940-8.

[25] Zhang Q, Mclellan BC, Tezuka T, Ishihara KN. A methodology for economic and environmental analysis of electric vehicles with different operational conditions. Energy 2013. http://dx.doi.org/10.1016/i.energy.2013.01.025.

[26] Borba BSM, Szklo A, Schaeffer R. Plug-in hybrid electric vehicles as a way to maximize the integration of variable renewable energy in power systems: the case of wind generation in northeastern brazil. Energy 2012;37(1):469-81.

[27] Muratori M, Moran MJ, Serra E, Rizzoni G. Highly-resolved modeling of personal transportation energy consumption in the united states. Energy 2013:58:168-77.

[28] Shafie-khah M, Moghaddam MP, Sheikh-El-Eslami MK, Rahmani-Andebili M. Modeling of interactions between market regulations and behavior of plug-in electric vehicle aggregators in a virtual power market environment. Energy 2012;40(1):139-50.

[29] Juul N. Battery prices and capacity sensitivity: electric drive vehicles. Energy 2012;47(1):403-10.
[30] Kiviluoma J, Meibom P. Methodology for modelling plug-in electric vehicles in the power system and cost estimates for a system with either smart or dumb electric vehicles. Energy 2011;36(3):1758-67.

[31] Hedegaard K, Ravn H, Juul N, Meibom P. Effects of electric vehicles on power systems in northern Europe. Energy 2012;48(1):356-68.

[32] Li Z, Ouyang M. The pricing of charging for electric vehicles in China dilemma and solution. Energy 2011;36(9):5765-78.

[33] Densing M, Turton H, BÃauml G. Conditions for the successful deployment of electric vehicles a global energy system perspective. Energy 2012:47(1):137-49.

[34] Kromer MA, Bandivadekar A, Evans C. Long-term greenhouse gas emission and petroleum reduction goals: evolutionary pathways for the light-duty vehicle sector. Energy 2010;35(1):387-97.

[35] Hao H, Wang H, Ouyang M. Fuel conservation and GHG (greenhouse gas) emissions mitigation scenarios for Chinas passenger vehicle fleet. Energy 2011;36(11):6520-8.

[36] Smith WJ. Can EV (electric vehicles) address Irelands $\mathrm{CO}_{2}$ emissions from transport? Energy 2010;35(12):4514-21.

[37] Sioshansi R, Denholm P. The value of plug-in hybrid electric vehicles as grid resources. Energy J 2010;31(3):1-24.

[38] Sioshansi R. Modeling the impacts of electricity tariffs on plug-in hybrid electric vehicle charging, costs, and emissions. Oper Res 2012;43(4):1199-204.

[39] Sousa T, Morais H, Soares J, Vale Z. Day-ahead resource scheduling in smart grids considering vehicle-to-grid and network constraints. Appl Energy 2012;96:183-93.

[40] Sioshansi R, Denholm P. Emissions impacts and benefits of plug-in hybrid electric vehicles and vehicle-to-grid services. Environ Sci Technol 2009;43(4) 1199-204.

[41] Batteries for electric drive vehicles status 2005. Electric Power Research Institute, EPRI; 2005.

[42] Nemhauser GL, Wolsey LA. Integer and combinatorial optimization, vol. 18 New York: Wiley; 1988.

[43] National household travel survey. U.S. Department of Transportation; 2011.

[44] Dynamic load profiles. Pasific Gas \& Electric; 2009.

[45] Impacts assessment of plug-in hybrid vehicles on electric utilities and regional U.S. power grids, part 1: technical analysis. U.S. Department of Energy; 2007.

[46] Modeling the performance and cost of lithium-ion batteries for electric-drive vehicles. Argonne National Laboratory; 2012.

[47] California distributed energy resources guide. California Energy Comission; 2012.

[48] Comperative costs of California central station electricity generation. California Energy Commission; 2010.

[49] Residential time-of-use service. Pasific Gas \& Electric; 2008.

[50] Distributed energy resource basics website. U.S. DOE Energy Efficiency and Renewable Energy (EERE); 2013a.

[51] Fuel economy guide. U.S. DOE Energy Efficiency and Renewable Energy (EERE); 2013b.

[52] Tier 2 vehicle and gasoline sulfur program. U.S. Environmental Protection Agency; 1999.

[53] California ISO. Daily renewables watch. Http://content.caiso.com/green/ renewrpt/DailyRenewablesWatch.pdf; [accessed 15.08.13] 